\title{
NHỬNG YẾU TỐ THÚC ĐẨY VÀ KÌM HÃM Ý ĐỊNH MUA THỰC PHẨM HỬU CƠ CỦA NGƯờI TIÊU DÙNG TẠI THÀNH PHỐ HỒ CHÍ MINH
}

\author{
HUỲNH THI KIM LOAN; NGUYỄN NGOQC HIỀN \\ Khoa Quản trị kinh doanh, Truờng Đại học Công nghiệp thành phố Hồ Chí Minh \\ nguyenngochien.qn@iuh.edu.vn
}

Tóm tắt: Thực phẩm hữu cơ trở nên phổ biến tại Việt Nam do mức độ nhận thức về thực phẩm không an toàn của người dân ngày càng nâng cao. Tuy nhiên thực phẩm hữu cơ không là lựa chọn tối ưu trong ý định tiêu dùng. Điều này cho thấy một khoảng cách tồn tại giữa ý định và nhận thức người tiêu dùng khi chọn mua thực phẩm hữu cơ, đó là yếu tố thúc đẩy hoặc kìm hãm. Vì vậy nghiên cứu nhằm mục đích xác định, đánh giá những yếu tố thúc đẩy và kìm hãm ý định mua thực phẩm hữu cơ. Với những thang đo được kế thừa từ các nghiên cứu trước, nghiên cứu định tính thông qua phỏng vấn sâu sơ bộ các chuyên gia có kiến thức nhất định về thực phẩm hữu cơ được thực hiện nhằm kiểm định mức độ phù hợp của thang đo đối với bối cảnh một đất nước đang phát triển như Việt Nam. Nghiên cứu định lượng sơ bộ với 77 quan sát hợp lệ nhằm đánh giá độ tin cậy thang đo. Với mẫu nghiên cứu chính thức gồm 299 người tiêu dùng, mô hình hồi quy tuyến tính đa biến được sử dụng để kiểm định giả thuyết nghiên cứu. Kết quả cho thấy ý thức sức khỏe, phúc lợi hệ sinh thái, an toàn chất lượng, rào cản giá trị, rào cản rủi ro, rào cản sử dụng là những yếu tố giải thích ý định mua thực phẩm hữu cơ. Một số hàm ý quản trị được đề xuất nhằm thu hút người tiêu dùng chọn mua thực phẩm hữu cơ.

Tù̀ khóa: ý định mua, thực phẩm hữu cơ, thúc đẩy, kìm hãm.

\section{FACILITATOR AND INHIBITOR FACTORS FOR THE ORGANIC FOOD PURCHASING INTENTION OF CONSUMERS IN HO CHI MINH CITY}

\begin{abstract}
Organic food has become popular in Vietnam due to the increasing awareness of people about unsafe food. However, organic food is not the optimal choice in terms of consumption intentions. This shows that a gap exists between the intention and perception of consumers when choosing to buy organic food, which is a motivating or inhibiting factor. Therefore, the study aims to identify and evaluate the factors that promote and inhibit the intention to buy organic food. With the scales inherited from previous studies, qualitative research through preliminary in-depth interviews with experts with certain knowledge about organic food was carried out to verify the relevance of the scale for the context of a developing country like Vietnam. Preliminary quantitative study with 77 valid observations to assess the reliability of the scale. With a formal research sample of 299 consumers, a multivariable linear regression model was used to test the research hypothesis. The results show that health consciousness, ecosystem welfare, quality safety, value barriers, risk barriers, and use barriers are the factors that explain the intention to buy organic food. Several governance implications are proposed to attract consumers to choose to buy organic food.
\end{abstract}

Key words: purchase intention, organic food, facilitator, inhibitor.

\section{GIỚI THIỆU}

Thực phẩm hữu cơ ngày càng được quan tâm vì thực phẩm trồng bằng hóa chất gây bất lợi với môi trường và ảnh hưởng đến sức khỏe của người dùng (Kushwah và cộng sự, 2019; Molinillo và cộng sự, 2020; Tandon và cộng sự, 2020). Các mô hình tiêu dùng trên toàn cầu cho thấy sự quan tâm ngày càng tăng của người tiêu dùng đối với thực phẩm hữu cơ, doanh số bán lẻ thực phẩm hữu cơ toàn cầu đã đạt 97 tỷ Euro vào năm 2018, tuy nhiên, sự phát triển của thị trường thực phẩm hữu cơ đã có xu hướng chậm lại (Willer và cộng sự, 2020). Các nghiên cứu đã chỉ ra sự khác biệt giữa thái độ và ý định mua thực phẩm hữu cơ, các yếu tố như: nhạy cảm về giá, lòng trung thành với sản phẩm đang sử dụng, v.v...đã dẫn đến người tiêu dùng phải đối mặt một số rào cản khi mua (Kushwah và cộng sự, 2019). Các học giả đã quan tâm nhiều 
khía cạnh khác nhau về ý định mua thực phẩm hữu cơ như: thái độ, đặc điểm cá nhân và gia đình, xu hướng tiêu dùng (Pham và cộng sự, 2019). Tuy nhiên có rất ít nghiên cứu tồn tại về những yếu tố thúc đẩy và kìm hãm ý định mua thực phẩm hữu cơ.

Tại Việt Nam, Chính phủ đã có những định hướng để phát triển thực phẩm hữu cơ. Nghị định 109/2018/NĐCP về văn hóa hữu cơ và các tiêu chuẩn an toàn thực phẩm nhằm thúc đẩy người dân sử dụng sản phẩm sạch, tiêu dùng xanh trong đó có thực phẩm hữu cơ để giải quyết những lo ngại của người dùng về các vấn đề liên quan đến hệ sinh thái môi trường, sức khỏe và an toàn thực phẩm. Nguyen và cộng sự (2019) chỉ ra rằng, ý thức sức khỏe liên quan đến thái độ tích cực đối với sự sằn sàng chi trả thực phẩm hữu cơ. Pham và cộng sự (2019) cho thấy rào cản ảnh hưởng ý định mua thực phẩm hữu cơ là thiếu thuận tiện và khó khăn tìm kiếm. Như vậy, các nghiên cứu tại Việt Nam về ý định mua thực phẩm hữu cơ vẫn còn khá ít, ngoài ra các nghiên cứu chỉ tập trung phân tích thực trạng để đưa ra giải pháp, một số ít nghiên cứu xem xét yếu tố ảnh hưởng ý định mua thực phẩm hữu cơ.

Mục tiêu nghiên cứu là xác định và đánh giá những yếu tố thúc đẩy và kìm hãm ý định mua thực phẩm hữu cơ. Để thực hiện mục tiêu trên, nghiên cứu đã sử dụng phương pháp nghiên cứu hỗn hợp cụ thể là phương pháp nghiên cứu định tính thông qua phỏng vấn sâu sơ bộ các chuyên gia có kiến thức nhất định về thực phẩm hữu cơ để kiểm định mức độ phù hợp của thang đo đối với bối cảnh một đất nước đang phát triển như Việt Nam, đặc biệt tại TP. Hồ Chí Minh. Phương pháp nghiên cứu định lượng được thực hiện bằng một bộ dữ liệu thu thập thông qua khảo sát trực tiếp bằng hệ thống bảng câu hỏi có cấu trúc để kiểm định các giả thuyết nghiên cứu.

Lý thuyết hành động hợp lý và lý thuyết hành vi dự định được sử dụng để cung cấp nền tảng cho sự hiểu biết về mối quan hệ giữa thái độ, ý định và hành vi. Lý thuyết nhân tố kép được sử dụng để giải thích ảnh hưởng đồng thời của yếu tố thúc đầy và kìm hãm cùng với lý thuyết phản kháng sự đổi mới để đánh giá sự phản kháng của người dùng đối với thực phẩm hữu cơ. Nghiên cứu có những đóng góp nhất định về mặt thực tiễn. Thứ nhất, nghiên cứu đánh giá một khoảng cách tồn tại giữa ý định và nhận thức người tiêu dùng khi chọn mua thực phẩm hữu cơ đó là yếu tố thúc đẩy và kìm hãm. Thứ hai, nghiên cứu làm sáng tỏ việc ra quyết định đằng sau việc chọn mua thực phẩm hữu cơ bằng cách phân định kép ảnh hưởng đồng thời của yếu tố thúc đẩy và kìm hãm. Từ đó đề xuất một số hàm ý quản trị và giải pháp hỗ trợ phát triển động cơ thúc đẩy, hạn chế kìm hãm cho người tiêu dùng khi chọn mua thực phẩm hữu cơ cũng như một số ý kiến đóng góp của cá nhân góp phần hỗ trợ những nhà sản xuất, các doanh nghiệp, tổ chức, v.v...đang kinh doanh, phân phối nhóm ngành thực phẩm nói chung và thực phẩm hữu cơ nói riêng có thể khắc phục, cải thiện, nâng cao chất lượng, dịch vụ chăm sóc người tiêu dùng để từ đó gia tăng nhận thức và phát triển ý định mua thực phẩm hữu cơ.

\section{CƠ SỞ LÝ THUYẾT}

\subsection{Thực phẩm hữu co'}

Theo Ghali \& Hamdi (2015), thực phẩm hữu cơ sản xuất dựa trên hệ thống canh tác tự nhiên, yêu cầu không sử dụng: phân bón hóa học, hóa chất bảo vệ thực vật, chất kích thích tăng trưởng, chất phụ gia và thành phần biến đổi gen. Sản xuất thực phẩm hữu cơ không gần nhà máy công nghiệp, quốc lộ. Nguồn nước tưới là nước giếng sạch, không được dùng công nghệ biến đổi gen kể cả công nghệ nano, quá trình chăm sóc cẩn thận và tự nhiên hóa. Thực phẩm hữu cơ gồm sản phẩm từ cây trồng (trái, hạt, củ, v.v...) và sản phẩm từ vật nuôi (thịt, trứng, sữa, v.v...). Ngoài lý do sử dụng thực phẩm hữu cơ an toàn, chất lượng hơn, các nghiên cứu đã thống kê thực phẩm hữu cơ giàu chất dinh dưỡng, có vị đậm đà hơn (Nguyen và cộng sự, 2019; Chekima và cộng sự, 2019). Thực phẩm hữu cơ thân thiện với môi trường, tự nhiên do đó lành mạnh hơn (Ditlevsen và cộng sự, 2019). Với quy trình sản xuất chặt chẽ, thực phẩm hữu cơ loại bỏ hoàn toàn chất độc hại và có hàm lượng dinh dưỡng nhiều hơn $50 \%$ (gồm khoáng chất, vitamin) so với thực phẩm khác (Kushwah và cộng sự, 2019; Tandon và cộng sự, 2020).

\section{2. Ý định mua và ý định mua thực phẩm hữu co}

Theo Lisa Beck và Icek Ajzen (1991), ý định chứa đựng động lực thúc đẩy, sẵn sàng thử, nỗ lực hoàn thành hành vi. Ngoài ra, ý định mua là sự sẵn sàng mua và tiếp tục sử dụng (Elbeck và Tirtiroglu, 2008). Dodds và cộng sự (1991) cho rằng ý định mua thể hiện khả năng mua sản phẩm nào đó. Ý định mua tượng trưng cho những gì một cá nhân muốn mua trong tương lai (Long và Ching, 2010). Dự đoán ý định mua là bước khởi đầu dự đoán hành vi mua (Howard và Sheth, 1967). Một số nghiên cứu chỉ ra điểm khác biệt giữa ý 
định mua và hành động mua đó là nhận thức (Mullett và Karson, 1985). Thêm vào đó dựa vào một số học thuyết, ý định mua là cơ sở dự đoán cầu trong tương lai (Bagozzi, 1982).

Blackwell (2005) biện luận ý định mua là yếu tố đánh giá khả năng thực hiện hành vi trong tương lai, thường được xem là một trong hai yếu tố ảnh hưởng hành vi mua. Ý định mua là những gì chúng ta nghĩ chúng ta sẽ mua (Huang và cộng sự, 2014). Theo Ajzen (1991), ý định ảnh hưởng trực tiếp bởi "thái độ", “chuẩn mực chủ quan" và "nhận thức kiểm soát hành vi”. Han và cộng sự (2009) cho rằng ý định mua thực phẩm hữu cơ gắn với truyền miệng sản phẩm. Ramayah và cộng sự (2010) cho rằng ý định mua thực phẩm hữu cơ là biểu hiện hành vi mua.

\subsection{Lý thuyết nền}

\subsubsection{Lý thuyết hành động hợp lý (TRA - Theory of Reasoned Action) và lý thuyết hành vi dụ định (TPB -} Theory of Planned Behavior)

Lý thuyết hành vi dự định được Ajzen phát triển năm 1985 dựa trên lý thuyết hành động hợp lý được đề xuất bởi Fishbein và Ajzen (1975). TRA cung cấp nền tảng cho sự hiểu biết về mối quan hệ giữa thái độ, ý định và hành vi. Theo TRA, ý định hành vi là yếu tố quyết định hành vi dựa trên các thông tin sẵn có. Do đó, thay vì nghiên cứu hành vi thì nghiên cứu này tập trung vào nghiên cứu ý định hành vi. Ý định chịu sự tác động của hai yếu tố là thái độ cá nhân và chuẩn mực chủ quan. Thái độ cá nhân được đo lường bằng niềm tin của người tiêu dùng đối với các thuộc tính sản phẩm và chuẩn mực chủ quan được đo lường thông qua những người liên quan. Ajzen (1991) nhận định rằng, người tiêu dùng không thể kiểm soát hoàn toàn hành vi của họ do đó lý thuyết TRA bị hạn chế khi dự đoán hành vi của người tiêu dùng. TPB được xây dựng bằng cách bổ sung thêm yếu tố nhận thức kiểm soát hành vi. Nhận thức kiểm soát hành vi phản ánh việc thực hiện hành vi đó là dễ dàng hay khó khăn, điều này phụ thuộc vào cơ hội để thực hiện hành vi và nguồn lực sẵn có (Ajzen, 1991).

\subsubsection{Lý thuyết phản kháng sụ đổi mới (IRT - Innovation Resistance Theory)}

Lý thuyết phản kháng sự đổi mới đưa ra giả thuyết về yếu tố kìm hãm thể hiện sự phản kháng một sản phẩm bất kì. Có ba rào cản chức năng là giá trị, sử dụng, rủi ro và hai rào cản tâm lý là truyền thống, hình ảnh (Ram \& Sheth, 1989). Mặc dù đã có sự chấp nhận về lợi ích thực phẩm hữu cơ, người dùng vẫn hoài nghi về lợi ích được công bố làm ngăn cản ý định mua. Nghiên cứu trước chỉ ra mức giá cao là rào cản đáng kể làm giảm giá trị cảm nhận thực phẩm hữu cơ (Kushwah và cộng sự, 2019). Sự thiếu tin tưởng tính xác thực, nhận thấy rủi ro khi chọn mua (Nuttavuthisit \& Thogersen, 2017). Một rào cản khác là thiếu thuận tiện, khó khăn tìm kiếm thực phẩm hữu cơ (Pham và cộng sự, 2019). Các rào cản tâm lý không đưa vào khuôn khổ giả thuyết nghiên cứu vì ở nghiên cứu trước đã thảo luận kỹ lưỡng (Van Doorn \&Verhoef, 2015; Birch và cộng sự, 2018; Shamsi và cộng sự, 2020). Vì vậy, nghiên cứu trình bày rào cản giá trị, sử dụng, rủi ro là ba yếu tố kìm hãm ý định mua thực phẩm hữu cơ.

\subsubsection{Lý thuyết nhân tố kép (DFT-Dual Factor Theory)}

Lý thuyết nhân tố kép giải thích ảnh hưởng đồng thời yếu tố thúc đẩy và kìm hãm ý định mua. Lý thuyết chỉ ra khi người dùng bị ảnh hưởng bởi hai nhóm yếu tố có tác động tích cực và tiêu cực thì họ phải đấu tranh tâm lý để thay đổi nhận thức làm thay đổi ý định ban đầu. Những ảnh hưởng này bao gồm yếu tố thúc đẩy việc chấp nhận thay đổi ý định theo hướng tích cực và yếu tố kìm hãm khiển người dùng chống lại ý định (Herzberg và cộng sự, 1996). Lý thuyết ứng dụng trong bối cảnh sử dụng công nghệ, ý định mua thực phẩm trực tuyến (Rey-Moreno \& Medina-Molina, 2020). Nghiên cứu của Tandon và cộng sự (2020a) mở rộng khả năng ứng dụng lý thuyết nhân tố kép để nhận thức ý định mua thực phẩm hữu cơ thông qua yếu tố thúc đẩy và kìm hãm.

\section{GIẢ THUYẾT VÀ MÔ HÌNH NGHIÊN CÚU}

\subsection{Giả thuyết nghiên cứu}

Ý thức sức khỏe là sự sẵn sàng cũng như mong muốn xác định và thực hiện các hành động có thể duy trì, cải thiện sức khỏe. Sức khỏe được định nghĩa là trạng thái tốt của thể lực, trí lực và sự hạnh phúc chứ không chỉ đơn thuần là tình trạng không bệnh tật hay không ốm yếu (Hansen và cộng sự, 2018; Nguyen và cộng sự, 2019). Một số nghiên cứu tuyên bố những cá nhân có ý thức sức khỏe sẽ mua thực phẩm hữu cơ vì sản phẩm không hóa chất, thành phần biến đổi gen (Hansen và cộng sự, 2018). Việc nuôi trồng thực phẩm hữu cơ không chất phụ gia là lựa chọn lành mạnh (Van Doorn \& Verhoef, 2015). Pham và cộng sự (2019) cho 
rằng nhận thức của người tiêu dùng nâng cao, họ nắm bắt lợi ích thực phẩm hữu cơ mang lại. Hơn nữa, Lee và Yun (2015) gợi ý rằng người tiêu dùng có nhận thức về ý thức sức khỏe sẽ chọn mua thực phẩm hữu cơ vì thành phần dinh dưỡng, tự nhiên cao góp phần cải thiện sức khỏe, do đó ý thức sức khỏe là yếu tố kích thích chọn mua thực phẩm hữu cơ. Dựa trên cuộc thảo luận trước, ý thức sức khỏe là yếu tố tác động tích cực ý định mua thực phẩm hữu cơ (Nguyen và cộng sự, 2019). Như vậy:

Giả thuyết $H_{1}$ : Ý thức sức khỏe tác động cùng chiều ý định mua thực phẩm hũu co

Phúc lợi hệ sinh thái là sự quan tâm của người dùng về bảo vệ môi trường và quyền lợi động vật trong quá trình sản xuất, đảm bảo sự phát triển bền vững của hệ sinh thái tự nhiên (Kushwah và cộng sự, 2019; Teng $\& \mathrm{Lu}, 2016)$. Các học giả tranh luận rằng người tiêu dùng được thúc đẩy tiêu thụ thực phẩm hữu cơ bởi sự quan tâm đến bảo vệ động vật, môi trường. Đối với chăn nuôi thông thường, tiêm chích hóc-môn tăng trưởng để động vật lớn nhanh nhằm cung ứng ra thị trường. Người dùng lo lắng khi sử dụng thực phẩm nuôi trồng theo cách thông thường sẽ ảnh hưởng không tốt sức khỏe cũng như mất cân bằng sinh thái, chết thảm thực vật (Bryła, 2016; Schrank \& Running, 2018). Ý thức bảo vệ hệ sinh thái đa dạng, quyền động vật ngày càng nâng cao, đó là lý do để họ chọn mua thực phẩm hữu cơ (Hansen và cộng sự, 2018). Trong một số trường hợp, người dùng sẵn sàng chọn mua thực phẩm hữu cơ vì họ được đóng góp vào việc duy trì cân bằng tự nhiên, thể hiện lòng vị tha (Kushwah và cộng sự, 2019). Do đó:

Giả thuyết $\mathrm{H}_{2}$ : Phúc lợi hệ sinh thái tác động cùng chiều ý định mua thực phẩm hũu co

An toàn chất lượng là sự quan tâm của người tiêu dùng đối với giá trị dinh dưỡng và hàm lượng vitamin, khoáng chất, quá trình sản xuất không có hóa chất hoặc các thành phần biến đổi gen của thực phẩm hữu cơ, tuân thủ các quy định canh tác đảm bảo sản phẩm đạt chất lượng, an toàn (Kareklas và cộng sự, 2014; Escobar-López và cộng sự, 2017). Thực phẩm hữu cơ được xem có chất lượng, an toàn sẽ ảnh hưởng tích cực thái độ người dùng (Bryła, 2016). Hơn nữa, người dùng quan tâm đến an toàn chất lượng vì thành phần dinh dưỡng, hàm lượng tự nhiên là yếu tố đáng để chọn mua (Fleseriu và cộng sự, 2020). Ditlevsen và cộng sự (2019) cho rằng thực phẩm hữu cơ tốt cho sức khỏe do hàm lượng thuốc trừ sâu thấp, dinh dưỡng cao. Theo nghiên cứu trước, thành phần dinh dưỡng có trong thực phẩm hữu cơ kích thích người dùng chọn mua (Schrank \& Running, 2018). Thực phẩm hữu cơ mang lại lợi ích cao khi sản phẩm có độ tươi, tinh khiết (Molinillo và cộng sự, 2020). Các học giả nhận thấy ảnh hưởng đáng kể của an toàn chất lượng thúc đẩy người dùng mua thực phẩm hữu cơ và sẵn sàng trả giá cao (Kareklas và cộng sự, 2014). Do đó:

Giả thuyết $H_{3}$ : An toàn chất lương tác động cùng chiều ý định mua thực phẩm hũu co

Rào cản giá trị là sự thận trọng khi chọn mua thực phẩm hữu cơ vì mức giá cao và giá trị đồng tiền phải chi tiêu để có được sản phẩm so với thời gian và công sức bỏ ra (Kushwah và cộng sự, 2019; Chekima và cộng sự, 2019; Laukkanen, 2016). Rào cản giá trị phát sinh khi người dùng nhận thấy thông tin về thực phẩm hữu cơ còn mập mờ, làm mất thời gian tìm kiếm. Họ cảm thấy lo lắng khi giá trị sản phẩm mới thấp hơn giá trị hiện tại (Laukkanen, 2016; Kushwah và cộng sự, 2019). Basha \& Lal (2019) nhận thấy giá cả đóng vai trò là rào cản lớn, ngăn cản quá trình chọn mua. Các học giả chỉ ra yếu tố thời gian, giá cả cao và giá trị đồng tiền bỏ ra là những rào cản giá trị chính, là nguyên nhân khiến người dùng phản đối lựa chọn mua thực phẩm hữu cơ. Như vậy:

Giả thuyết $H_{4}$ : Rào cản giá trị tác động ngược chiều ý định mua thực phẩm hũu co

Rào cản sử dụng là sự thận trọng trong việc chọn mua thực phẩm hữu cơ do không phù hợp với yêu cầu người tiêu dùng khi thiếu hụt sản phẩm, phải chấp nhận sản phẩm mới (Chekima và cộng sự, 2019; Laukkanen, 2016). Rào cản sử dụng nảy sinh khi người dùng cảm nhận sản phẩm không mang lại trải nghiệm tốt như trước, không phù hợp thói quen, không thể chấp nhận sản phẩm mới (Ram \& Sheth, 1989). Người tiêu dùng quan tâm giá cả nhiều hơn so với lợi ích mà chúng mang lại (Nguyen và cộng sự, 2019). Họ có thói quen chọn mua sản phẩm tồn tại trong tâm trí, hài lòng, trung thành sản phẩm đang tiêu dùng, không mong muốn thay đổi cho dù sản phẩm mới có cùng chức năng hay đặc tính tương tự (Pham và cộng sự, 2019; Nuttavuthisit \& Thogersen, 2017). Các học giả cho rằng người dùng phải đối mặt với thách thức trong việc mua thực phẩm hữu cơ như: khó khăn tìm kiếm thông tin, không dễ dàng tìm các cửa hàng kinh doanh thực phẩm hữu cơ uy tín. Nhiều nghiên cứu xác nhận những yếu tố trên hoạt động như yếu tố kìm hãm ý định mua thực phẩm hữu cơ (Kushwah và cộng sự, 2019; Bryła, 2016). Vì vậy:

Giả thuyết $H_{5}$ : Rào cản sủ dụng tác động ngược chiều ý định mua thực phẩm hũu co 
Rào cản rủi ro là sự không chắc chắn về tính xác thực của sản phẩm có sẵn cũng như thiếu tin tưởng vào chứng nhận, quy trình sản xuất và sự bất tiện về mặt thông tin (Kushwah và cộng sự, 2019; Chekima và cộng sự, 2019; Laukkanen, 2016). Trong vấn đề mua sắm, mức độ rủi ro tăng lên do người tiêu dùng hạn chế khả năng tiếp cận sản phẩm mới. Các học giả đã nghiên cứu những rào cản rủi ro khi chọn mua thực phẩm hữu cơ: sự nghi ngờ quy trình chứng nhận, tính xác thực nhãn mác hoặc giấy chứng nhận đạt chuẩn. Những rào cản rủi ro khiến người dùng không chọn mua, không tin tưởng các bên liên quan: nông dân, nhà bán lẻ, công ty. Nhiều nghiên cứu cho rằng người dùng hoài nghi tính xác thực, quy trình sản xuất cũng như giấy chứng nhận đạt chuẩn chưa tin cậy, nghi ngờ nhãn mác không chính xác. Điều này đóng vai trò là rào cản ảnh hưởng tiêu cực ý định mua thực phẩm hữu cơ (Kushwah và cộng sự, 2019; Nuttavuthisit \& Thogersen, 2017). Theo Basha \& Lal (2019) cho rằng sự thiếu rõ ràng về nhãn hiệu cũng như chức năng liên quan đến từng thực phẩm hữu cơ. Vì vậy sự nhầm lẫn của người tiêu dùng phát sinh liên quan đến chứng nhận nhãn sinh thái, khó khăn khi phân biệt thực phẩm hữu cơ nên đã ảnh hưởng ý định mua. Do đó:

Giả thuyết $H_{6}$ : Rào cản rủi ro tác động ngược chiều ý định mua thực phẩm hũu co

\subsection{Mô hình nghiên cứu đề xuất}

Dựa vào lý thuyết hành động hợp lý (TRA - Theory of Reasoned Action) và lý thuyết hành vi dự định (TPB - Theory of Planned Behavior), lý thuyết nhân tố kép (DFT- Dual Factor Theory), lý thuyết phản kháng sự đổi mới (IRT - Innovation Resistance Theory) và các nghiên cứu trước. Mô hình nghiên cứu được đề xuất gồm 06 giả thuyết (Hình 1).

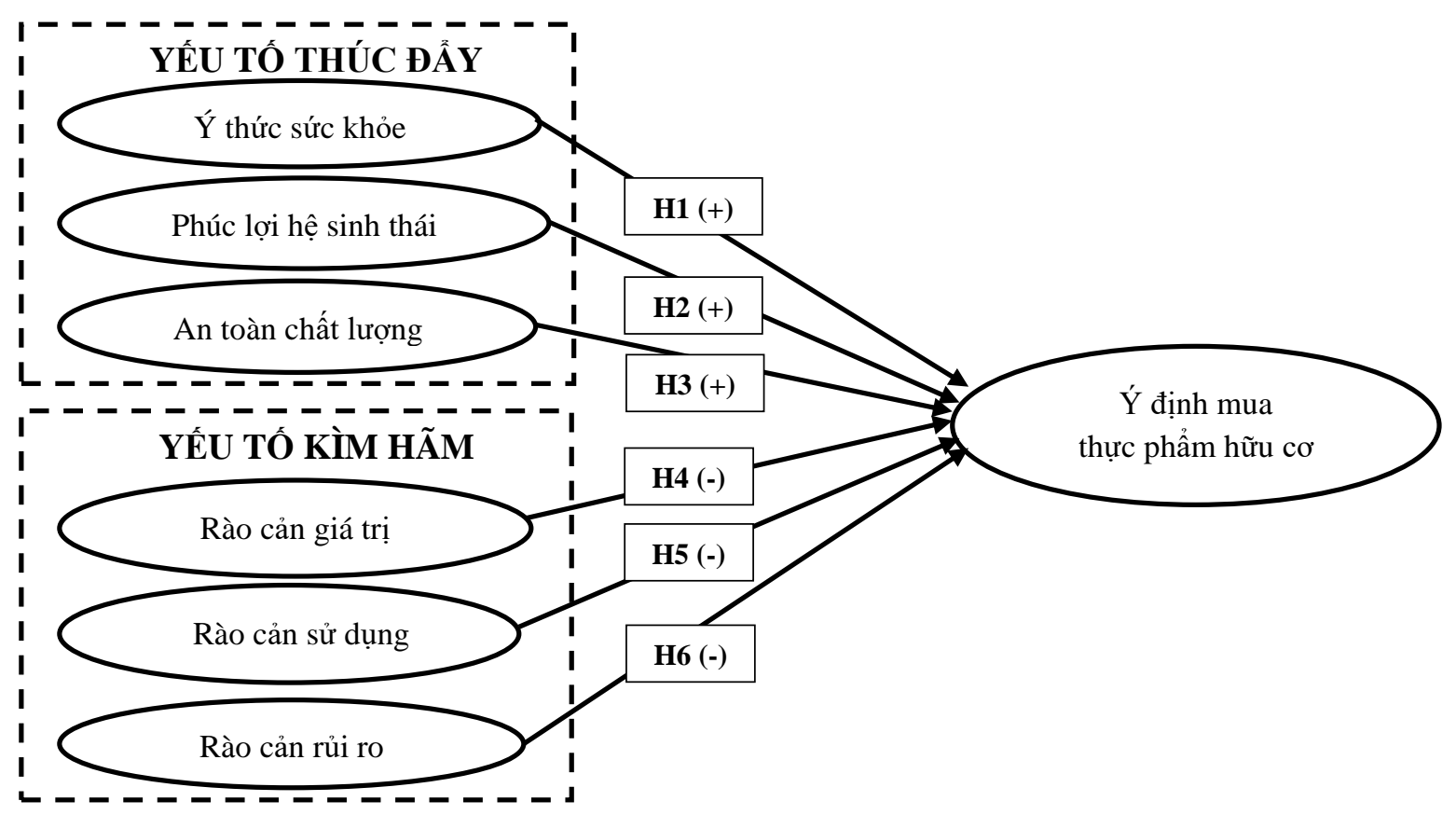

Hình 1: Mô hình nghiên cứu đề xuất

Nguồn: Tác giả tổng hợp tù giả thuyết nghiên cưu

\section{PHƯƠNG PHÁP NGHIÊN CÚU}

\section{1 Đo lường}

Nghiên cứu sử dụng thang đo lường của các nghiên cứu trước đã kiểm định trong những bối cảnh khác nhau. Phỏng vấn sâu 07 chuyên gia trong lĩnh vực tiêu dùng xanh được thực hiện vào tháng 12/2020 nhằm điều chỉnh các câu hỏi phù hợp với bối cảnh nghiên cứu. Kết quả cho thấy, cơ bản chấp thuận nội dung trong bản thảo câu hỏi điều tra. Tuy nhiên, một số câu hỏi chưa rõ ràng về nội dung cũng như những khái niệm lý thuyết còn mới tại Việt Nam, từ ngữ khó hiểu. Do đó, các ý kiến cho rằng giá trị yếu tố thúc đẩy, kìm hãm và ý định mua cần điều chỉnh từ ngữ để phù hợp hơn bối cảnh Việt Nam. Sau khi điều chỉnh, các thang đo được trình bày trong bảng 1 . Tất cả các thang đo cấu trúc được đo lường bằng thang đo Likert 5 
điểm từ Rất không đồng ý (1) đến Rất đồng ý (5). Ngoài ra, bảng câu hỏi bao gồm 4 câu hỏi về nhân khẩu học liên quan đến giới tính, độ tuổi, thu nhập và nghề nghiệp.

Bảng 1: Cấu trúc, thang đo lường và nguồn tham khảo

\begin{tabular}{|c|c|}
\hline Khái niệm và Biến quan sát & Nguồn \\
\hline $\begin{array}{l}\text { Phúc lợi hệ sinh thái }(\mathbf{E W}) \\
\text { Tôi cảm nhận thực phẩm hữu cơ... } \\
\text { EW1. Góp phần giảm thuốc diệt cỏ, phân bón hóa học, thuốc trừ sâu. } \\
\text { EW2. Thân thiện môi trường. } \\
\text { EW3. Không gây hại cho động vật. } \\
\text { EW4. Bảo vệ quyền động vật. }\end{array}$ & Teng \& Lu (2016) \\
\hline $\begin{array}{l}\text { An toàn chất lượng (QS) } \\
\text { Tôi cảm nhận thực phẩm hữu cơ... } \\
\text { QS1. Chứa nhiều vitamin và khoáng chất. } \\
\text { QS2. Chứa hàm lượng dinh dưỡng nhiều hơn. } \\
\text { QS3. Không sử dụng chất phụ gia. } \\
\text { QS4. Chứa nhiều chất đạm. } \\
\text { QS5. Không chứa dư lượng hóa chất và hóc-môn tăng trưởng. }\end{array}$ & $\begin{array}{l}\text { Escobar López và } \\
\text { cộng sự (2017); } \\
\text { Kareklas và cộng } \\
\text { sự (2014) }\end{array}$ \\
\hline $\begin{array}{l}\text { Ý thức sức khỏe (HC) } \\
\text { HC1. Tôi là người quan tâm sức khỏe. } \\
\text { HC2. Tôi lo lắng biểu hiện của sức khỏe khi sử dụng thực phẩm không an toàn. } \\
\text { HC3. Tôi nhận thức nên sử dụng thực phẩm nào là tốt và an toàn cho sức khỏe. } \\
\text { HC4. Tôi luôn mong muốn tìm kiếm thông tin về dinh dưỡng và chế độ ăn uống lành mạnh } \\
\text { nhằm cải thiện sức khỏe. } \\
\text { HC5. Tập thể dục và ăn uống lành mạnh là một phần trong thói quen của tôi. } \\
\text { HC6. Tôi sẵn sàng mua sắm để ăn uống tốt nhâtt cho sức khỏe. }\end{array}$ & $\begin{array}{c}\text { Hansen và cộng } \\
\text { sự (2018) }\end{array}$ \\
\hline $\begin{array}{l}\text { Rào cản giá trị (VB) } \\
\text { VB1. Tôi thấy giá cả thực phẩm hữu cơ cao hơn thực phẩm khác. } \\
\text { VB2. Tôi thây thông tin thực phẩm hữu cơ còn mang tính quảng cáo, làm mất thời gian tìm } \\
\text { kiếm. } \\
\text { VB3. Tôi mất thời gian so sánh giá cả từ cửa hàng kinh doanh thực phẩm hữu cơ. } \\
\text { VB4. Tôi lo ngại số tiền bỏ ra để chọn mua thực phẩm hữu cơ không xứng đáng với giá trị } \\
\text { nhận được. }\end{array}$ & $\begin{array}{c}\text { Tandon và cộng } \\
\text { sự (2020); } \\
\text { Kushwah và cộng } \\
\text { sự (2019) }\end{array}$ \\
\hline $\begin{array}{l}\text { Rào cản rủi ro (RB) } \\
\text { RB1. Tôi nghi ngờ nhãn mác in trên bao bì là không chính xác. } \\
\text { RB2. Tôi sợ rằng giấy chứng nhận đạt chuẩn chưa tin cậy. } \\
\text { RB3. Tôi lo lắng thực phẩm hữu cơ có sẵn trên thị trường không có chất lượng tốt. } \\
\text { RB4. Tôi thấy khó khăn đánh giá chất lượng thực phẩm hữu cơ. } \\
\text { RB5. Tôi nhận thấy khó phân biệt thực phẩm hữu cơ với thực phẩm khác. }\end{array}$ & $\begin{array}{c}\text { Tandon và cộng } \\
\text { sự (2020); } \\
\text { Nuttavuthisit \& } \\
\text { Thøgersen (2017) }\end{array}$ \\
\hline $\begin{array}{l}\text { Rào cản sử dụng (UB) } \\
\text { UB1. Tôi cảm nhận thực phẩm hữu cơ có hạn sử dụng ngắn nên dễ hư hỏng, khó bảo quản. } \\
\text { UB2. Tôi nhận thấy không dễ dàng tìm được cửa hàng kinh doanh thực phẩm hữu cơ uy tín. } \\
\text { UB3. Tôi đã quen nhãn hiệu sản phẩm đang sử dụng, việc sử dụng thực phẩm hữu cơ yêu } \\
\text { cầu bắt đầu thói quen mới. } \\
\text { UB4. Nơi tôi thường mua thực phẩm thì không kinh doanh thực phẩm hữu cơ. }\end{array}$ & $\begin{array}{l}\text { Kushwah và cộng } \\
\text { sự (2019); Pham } \\
\text { và cộng sự (2019) }\end{array}$ \\
\hline
\end{tabular}




\section{Ý định mua thực phẩm hữu cơ (PI)}

PI1. Khi có sự lựa chọn giữa hai loại thực phẩm có công dụng, chức năng tương tự nhau, tôi sẽ chọn mua loại thực phẩm góp phần bảo vệ môi trường.

PI2. Tôi có khả năng sẽ mua thực phẩm hữu cơ trong thời gian tới.

PI3. Tôi sẽ chủ động tìm kiếm thực phẩm hữu cơ để tiêu dùng.

Shamsi và cộng sự (2020)

PI4. Tôi sẵn sàng mua thực phẩm hữu cơ thay vì thực phẩm khác.

PI5. Tôi sẽ giới thiệu thực phẩm hữu cơ đến người thân và bạn bè.

Nguồn: Tác giả tổng hợp và điều chỉnh tùu nghiên cứu truớc

\subsection{Thu thập dữ liệu}

Nghiên cứu sơ bộ thực hiện phỏng vấn trực tiếp 100 người tiêu dùng vào tháng 01/2021 và có 77 quan sát hợp lệ. Kết quả tất cả giá trị Cronbach's Alpha của các khái niệm nằm trong khoảng từ 0.711 đến 0.845 lớn hơn 0.6 , hệ số tương quan biến - tổng đều lớn hơn 0.3 . Vì vậy, tất cả thang đo đều đạt độ tin cậy cần thiết theo đề xuất của Hair và cộng sự (2010) và được tổng hợp cho nghiên cứu chính thức.

Nghiên cứu chính thức thực hiện phỏng vấn trực tiếp tại TP.Hồ Chí Minh, đối tượng khảo sát từ 18 đến 65 tuổi - biết đến thực phẩm hữu cơ và có những đặc điểm nhân khẩu khác nhau (Bảng 1 ). Sau khi loại những phiếu không phù hợp (chọn đáp án ngẫu nhiên, không điền đầy đủ, chỉ điền 1 mức độ cho hầu hết câu hỏi), có 299 bảng hợp lệ được phân tích để đánh giá độ tin cậy, tính hợp lệ và tính phù hợp của giả thuyết.

\section{KẾT QUẢ NGHIÊN CÚU}

\section{1 Đặc điểm mẫu thống kê}

Bảng 1: Cơ cấu mẫu nghiên cứu chính thức (n=299)

\begin{tabular}{|c|c|c|c|c|c|}
\hline Giới tính & Tần số & \% & Độ tuổi & Tần số & \% \\
\hline Nam & 131 & 43.8 & Từ 18 đến 24 tuổi & 107 & 36.1 \\
\hline Nữ & 168 & 56.2 & Từ 25 đến 30 tuổi & 118 & 39.2 \\
\hline Nghề nghiệp & Tần số & $\%$ & Từ 31 đến 39 tuổi & 45 & 15.0 \\
\hline Học sinh - Sinh viên & 75 & 25.1 & Từ 40 đến 65 tuổi & 29 & 9.7 \\
\hline Nhân viên văn phòng & 98 & 32.8 & Thu nhập & Tần số & \% \\
\hline Lao động tự do & 14 & 4.6 & Thấp hơn 14 triệu đồng/tháng & 132 & 44.1 \\
\hline Cán bộ - công nhân viên & 55 & 18.4 & Từ 14 đến dưới 20 triệu đồng/tháng & 93 & 31.2 \\
\hline Doanh nhân, kinh doanh tự do & 39 & 13.1 & Từ 20 triệu đồng/tháng trở lên & 74 & 24.7 \\
\hline Khác & 18 & 6.0 & & & \\
\hline
\end{tabular}

Nguồn: Tác giả tổng hợp tù dũ liệu khảo sát

Kết quả cho thấy người trả lời có đặc điểm chủ yếu: giới tính nữ (168 người, chiếm $56.2 \%$ ), độ tuổi từ 18 đến 30 tuổi (225 người, chiếm $75.3 \%)$, nghề nghiệp chủ yếu là học sinh, sinh viên, nhân viên văn phòng (173 người, chiếm 57.9\%), thu nhập phổ biến thấp hơn 14 triệu đồng/tháng (132 người, chiếm 44.1\%).

\subsection{Kết quả đánh giá độ tin cậy của thang đo}

Tất cả giá trị Cronbach's Alpha của các khái niệm nằm trong khoảng từ 0.676 đến 0.801 , hệ số tương quan biến - tổng của tất cả các biến lớn hơn 0.339 . Vì vậy, tất cả thang đo đều đạt độ tin cậy cần thiết theo đề xuất của Hair và cộng sự (2010).

\subsection{Kết quả phân tích nhân tố khám phá}

Kết quả phân tích nhân tố khám phá cho các biến độc lập cho thấy có 6 nhân tố được trích, 28 biến quan sát đều có hệ số tải nhân lớn hơn 0.5 , biến nhân tố và biến quan sát có liên hệ chặt chẽ với nhau. Hệ số KMO có giá trị 0.893 lớn hơn 0.5 do đó phân tích nhân tố thích hợp với dữ liệu thực tế. Kiểm định Bartlett's Test có giá trị Sig. là 0.000 nhỏ hơn 0.05 chứng tỏ các biến quan sát tương quan trong cùng một nhân tố. Giá trị Eigenvalues là 1.038 lớn hơn 1 do đó các biến quan sát đạt yêu cầu đại diện cho phần biến thiên được giải thích bởi nhân tố tạo thành. 6 nhân tố giải thích $52.603 \%$ sự biến thiên của biến quan sát. 
Kết quả phân tích nhân tố khám phá cho biến phụ thuộc cho thấy hệ số KMO có giá trị là 0.834 lớn hơn 0.5 do đó phân tích nhân tố thích hợp với dữ liệu thực tế. Kiểm định Bartlett's Test có giá trị Sig. là 0.000 nhỏ hơn 0.05 do đó các biến quan sát tương quan với nhau trong nhân tố phụ thuộc. Giá trị Eigenvalues là 2.781 lớn hơn 1 do đó nhân tố rút ra có ý nghĩa tóm tắt thông tin tốt nhất. Số nhân tố được trích từ 5 biến quan sát là 1 nhân tố. 1 nhân tố giải thích $55.615 \%$ sự biến thiên của biến quan sát. Các biến quan sát có hệ số tải nhân đều lớn hơn 0.5 , cho thấy biến nhân tố và biến quan sát có liên hệ chặt chẽ với nhau.

Kết quả phân tích nhân tố khám phá thỏa mãn các điều kiện kiểm định theo đề xuất của Hair và cộng sự (2010), thu được mô hình hội tụ có khả năng giải thích, phân tích tốt nhất. Các nhân tố đảm bảo yêu cầu khi phân tích hồi quy bội.

\subsection{Kết quả phân tích hồi quy tuyến tính đa biến và kiểm định giả thuyết}

Kết quả 6 biến độc lập đều có giá trị Sig. là 0.000 nhỏ hơn 0.01 cho thấy mô hình hồi quy tuyến tính xây dựng được phù hợp với tổng thể, các biến độc lập tương quan tuyến tính với biến phụ thuộc. Các hệ số VIF đều dưới 10 chứng tỏ không có hiện tượng đa cộng tuyến theo đề xuất của Hair và cộng sự (2010).

\begin{tabular}{|c|c|c|c|c|c|c|c|}
\hline & & & & & & & \\
\hline \multirow[t]{2}{*}{ Mô hình } & \multicolumn{2}{|c|}{$\begin{array}{c}\text { Hệ số hồi quy chưa } \\
\text { chuẩn hóa }\end{array}$} & \multirow{2}{*}{$\begin{array}{c}\begin{array}{c}\text { Hệ số hồi } \\
\text { quy chuẩn } \\
\text { hóa }\end{array} \\
\text { Beta }\end{array}$} & \multirow[t]{2}{*}{$\mathbf{t}$} & \multirow[t]{2}{*}{ Sig. } & \multicolumn{2}{|c|}{$\begin{array}{l}\text { Kiểm tra hiện tượng đa } \\
\text { cộng tuyến }\end{array}$} \\
\hline & B & Std.Error & & & & Tolerance & VIF \\
\hline Hằng số & 3.161 & 0.316 & & 9.999 & 0.000 & & \\
\hline Ý thức sức khỏe & 0.249 & 0.055 & 0.180 & 4.532 & 0.000 & 0.721 & 1.386 \\
\hline Phúc lọ̣i hệ sinh thái & 0.248 & 0.048 & 0.217 & 5.116 & 0.000 & 0.634 & 1.577 \\
\hline An toàn chất lượng & 0.174 & 0.048 & 0.166 & 3.586 & 0.000 & 0.534 & 1.873 \\
\hline Rào cản giá trị & -0.202 & 0.042 & -0.184 & -4.757 & 0.000 & 0.763 & 1.311 \\
\hline Rào cản sử dụng & -0.197 & 0.046 & -0.188 & -4.298 & 0.000 & 0.599 & 1.670 \\
\hline Rào cản rủi ro & -0.270 & 0.045 & -0.271 & -5.998 & 0.000 & 0.559 & 1.789 \\
\hline
\end{tabular}

Nguồn: Tác giả tổng hợp tì dũ liệu khảo sát

Qua bảng thống kê về những yếu tố thúc đẩy và kìm hãm ý định mua thực phẩm hữu cơ thì 3 yếu tố thúc đẩy tác động cùng chiều ý định mua thực phẩm hữu cơ, trong đó phúc lợi hệ sinh thái tác động mạnh nhất $(\beta=0.217)$, kế đến ý thức sức khỏe $(\beta=0.180)$, cuối cùng an toàn chất lượng $(\beta=0.166)$. Và 3 yếu tố kìm hãm tác động ngược chiều ý định mua thực phẩm hữu cơ, trong đó rào cản rủi ro tác động mạnh nhất ( $\beta=$ $-0.271)$, kế đến rào cản sử dụng $(\beta=-0.188)$ và cuối cùng rào cản giá trị $(\beta=-0.184)$.

\subsection{Thảo luận kết quả nghiên cứu}

Kết quả của nghiên cứu có những nét tương đồng so với nghiên cứu trước: Thứ nhất đều đánh giá yếu tố ý thức sức khỏe, rào cản giá trị, rào cản rủi ro là những yếu tố giải thích ý định mua thực phẩm hữu cơ; thứ hai đều kiểm định ý thức sức khỏe tác động cùng chiều ý định mua và rào cản giá trị, rào cản rủi ro tác động ngược chiều ý định mua thực phẩm hữu cơ. Tuy nhiên, kết quả của nghiên cứu có những điểm khác biệt so với các nghiên cứu trước: Thứ nhất, yếu tố ý thức sức khỏe của nghiên cứu này không là yếu tố tác động mạnh nhất đến ý định mua thực phẩm hữu cơ, thay vào đó yếu tố phúc lợi hệ sinh thái được đánh giá có tác động mạnh nhất thúc đẩy ý định mua thực phẩm hữu cơ. Thứ hai, nghiên cứu xác định rào cản sử dụng là yếu tố kìm hãm ý định mua thực phẩm hữu cơ mặc dù các nghiên cứu được kế thừa cho rằng rào cản sử dụng không có mối liên hệ với ý định mua thực phẩm hữu cơ. Cuối cùng, các nghiên cứu trước nhận định rào cản giá trị là yếu tố kìm hãm mạnh nhất, tuy nhiên kết quả nghiên cứu này cho thấy rào cản giá trị là yếu tố kìm hãm tác động yếu nhất ý định mua thực phẩm hữu cơ.

\section{KẾT LUẬN VÀ HÀM Ý QUẢN TRI}

\subsection{Kết luận}

Nghiên cứu đã kiểm định mức độ tác động của những yếu tố thúc đẩy và kìm hãm ý định mua thực phẩm hữu cơ với mức độ tin cậy 99\%, góp phần cung cấp thông tin chi tiết về những thúc đẩy và kìm hãm tiềm 
ẩn đối với ý định mua thực phẩm hữu cơ. Đây là nghiên cứu để đánh giá những yếu tố thúc đẩy và kìm hãm ý định mua thực phẩm hữu cơ tại TP. HCM nên kểt quả và định hướng cách làm sẽ giúp ích cho những bài nghiên cứu sau này về động cơ thúc đẩy, rào cản kìm hãm trong quá trình chọn mua thực phẩm nói chung và thực phẩm hữu cơ nói riêng. Mặt khác, nghiên cứu góp phần củng cố nền tảng lý thuyết cho các bài nghiên cứu trước đây cũng như đóng góp vào lĩnh vực nghiên cứu một mô hình mới phù hợp với tình hình thực tế tại $\mathrm{VN}$, tiêu biểu là TP. HCM. Nghiên cứu đã đánh giá một khoảng cách tồn tại giữa ý định và nhận thức người tiêu dùng khi chọn mua thực phẩm hữu cơ đó là yếu tố thúc đẩy và kìm hãm, làm sáng tỏ quá trình ra quyết định đằng sau việc chọn mua thực phẩm hữu cơ bằng cách phân định kép các ảnh hưởng đồng thời của yếu tố thúc đẩy và kìm hãm. Nghiên cứu đề xuất một số hàm ý quản trị góp phần hỗ trợ doanh nghiệp, công ty nhận thức những yếu tố thúc đẩy và kìm hãm, từ đó thực hiện chiến lược phù hợp góp phần nâng cao hiệu quả hoạt động công ty, đồng thời đóng góp vào việc cân bằng hệ sinh thái cũng như đảm bảo sức khỏe người tiêu dùng khi chọn mua thực phẩm hữu cơ.

\subsection{Hàm ý quản trị}

Thứ nhất đối với yếu tố Phúc lợi hệ sinh thái, các doanh nghiệp kinh doanh thực phẩm hữu cơ cần hiểu rõ mối quan hệ giữa con người với tự nhiên để thực hiện chiến lược sản xuất nhằm bảo vệ môi trường sống, đảm bảo cân bằng hệ sinh thái vì họ là cầu nối khích lệ người dùng chọn mua, sử dụng. Hơn nữa doanh nghiệp cần tăng cường tuyên truyền nhằm nâng cao nhận thức về tiêu dùng xanh, ý thức bảo tồn thiên nhiên thông qua chương trình đào tạo ở các cấp học. Khi thái độ lo ngại đối với môi trường sống được nâng cao, người tiêu dùng sẽ thực hiện các hành động vị tha hơn, vì lợi ích xã hội hơn lợi ích cá nhân, góp phần phát triển ý định mua thực phẩm hữu cơ.

Thứ hai đối với yếu tố Ý thức sức khỏe, nhà sản xuất cung cấp những sản phẩm đem lại lợi ích sức khỏe ngày càng cao nhằm đem đến giá trị cốt lôi không chỉ cung ứng sản phẩm tốt mà còn đem lại giá trị cuộc sống. Các doanh nghiệp nên thực hiện chương trình tư vấn dinh dưỡng để cung cấp thông tin về chế độ ăn uống lành mạnh để cải thiện, duy trì sức khỏe. Ngoài ra cần đẩy mạnh hoạt động tiếp thị về những lợi ích của thực phẩm hữu cơ, chỉ ra tác hại khi sử dụng các thực phẩm bẩn sẽ ảnh hưởng đến tình trạng sức khỏe và đe dọa tính mạng.

Thứ ba đối với yếu tố An toàn chất lượng, doanh nghiệp cần ý thức trách nhiệm, lương tâm đạo đức nghề nghiệp, tuân thủ nghiêm ngặt quy trình sản xuất, rà soát quá trình trồng trọt, chăn nuôi đến thu hoạch, chế biến, cung ứng ra thị trường và kiểm định kỹ lưỡng sản phẩm theo các tiêu chuẩn trước khi kinh doanh. Các sản phẩm hết hạn sử dụng cần loại bỏ, đảm bảo độ tươi ngon không chỉ làm tăng uy tín thương hiệu doanh nghiệp mà còn tạo lòng tin, làm tăng ý định mua.

Thứ tư đối với yếu tố Rào cản rủi ro, các doanh nghiệp cần xây dựng hệ thống nhận diện thương hiệu giúp mọi người dễ dàng nhận biết thương hiệu, thiết kế bao bì, kiểu dáng, mẫu mã bắt mắt, tên nhãn hiệu ngắn gọn, dễ nhớ, đẩy mạnh hoạt động chiêu thị bằng cách tổ chức chương trình dùng thử sản phẩm, tiếp thị, khuyến mãi hoặc tặng kèm để họ có cơ hội biết đến, sử dụng và tự cảm nhận về thực phẩm hữu cơ. Thông tin sản phẩm mập mờ làm cho người mua không kiểm tra được nguồn gốc xuất xứ, thành phần, v.v... Do đó nhà sản xuất cần cung cấp thông số ghi trên nhãn mác, bao bì đầy đủ, đúng sự thật, có các chứng nhận đã kiểm định, thực hiện đúng cam kết về chất lượng hàng hóa, chính sách đổi trả minh bạch, cung cấp đầy đủ thông tin: tên cửa hàng đã đăng kí, giấy tờ, hóa đơn, hình ảnh chứng minh nguồn gốc hàng hóa, v.v..., trung thực trong quảng cáo, không nói sai, nói quá sự thật, sản phẩm đầy đủ thông tin ngày sản xuất, hạn sử dụng, hướng dẫn sử dụng, địa chỉ nhà sản xuất, v.v..., công bố trên phương tiện truyền thông của công ty: email, website, ấn phẩm, nhãn mác, v.v..., tạo chế độ bình luận, chia sẻ công khai dành cho người tiêu dùng đã trải nghiệm sản phẩm.

Thứ năm đối với yếu tố Rào cản sử dụng, gia tăng điểm bán ở những quận, huyện: Nhà Bè, Quận 9, v.v..., tăng cường hợp tác với đại lý chưa kinh doanh thực phẩm hữu cơ để mở rộng hệ thống. Cửa hàng cần trưng bày sản phẩm ở khu vực sạch sẽ, bảo quản ở nhiệt độ phù hợp giúp người dùng dễ dàng tìm kiếm. Sự tương tác giữa nhân viên và người tiêu dùng đóng vai trò quan trọng góp phần quyết định khả năng quay lại vì vậy cần tuyển dụng, đào tạo nhân viên có tác phong chuyên nghiệp, trung thực khi giới thiệu sản phẩm, nói đúng những lợi ích và mạnh dạn nói hạn chế. Các doanh nghiệp nên tận dụng mạng xã hội để quảng bá hình ảnh, cung cấp thông tin hữu ích, xây dựng đội ngũ quản lý trang web liên kết ứng dụng bán hàng trực tuyến, giải đáp thắc mắc của người dùng. 
Cuối cùng đối với yếu tố Rào cản giá trị, nhà sản xuất cần cân nhắc chính sách giá cả, chia nhỏ sản phẩm theo trọng lượng giúp người mua có nhiều lựa chọn hợp lý. Nhà nước cần hỗ trợ doanh nghiệp tiếp cận nguồn tài chính: chính sách vốn, chi phí nguyên liệu, v.v... Bình ổn giá là vấn đề quan tâm vì giá ổn định sẽ giúp họ an tâm, không hoài nghi về chất lượng sản phẩm. Hơn nữa để duy trì̀, thu hút khách hàng thì giảm giá, khuyến mãi là lựa chọn tối ưu. Nhà sản xuất có thể áp dụng mức giá chiết khấu với đại lý, nhà bán lẻ để mở rộng hợp tác với cửa hàng chưa kinh doanh thực phẩm hữu cơ vừa khắc phục tình trạng nhỏ lẻ vừa đem sản phẩm đến người dùng gần hơn. Ngoài ra người mua thường so sánh giá ở các điểm bán do đó cần liên kết giữa nhà sản xuất đến nhà thu mua để thắt chặt cung cấp mức giá giống nhau, hoặc chênh lệch thấp tại cửa hàng. Đôi lúc người dùng né tránh trang quảng cáo vì mất thời gian, do đó nhà sản xuất cần hiểu rõ tâm lý người mua, cung cấp thông tin ngắn gọn mà vẫn đảm bảo nội dung truyền tải và trước khi đăng quảng cáo cần đăng kí, thông báo với Bộ Công Thương để cấp logo chứng nhận làm tăng mức độ uy tín thương hiệu.

\subsection{Hạn chế nghiên cứu}

Thứ nhất, nghiên cứu áp dụng chọn mẫu thuận tiện để tiết kiệm thời gian, chi phí, dễ dàng tiếp cận và lấy thông tin, tuy nhiên độ chính xác chưa cao khi kết luận kết quả tổng thể, hạn chế khái quát hóa dữ liệu. Thứ hai, nghiên cứu thực hiện với mẫu giới hạn phạm vi người tiêu dùng biểt đến thực phẩm hữu cơ tại TP. HCM, do đó khả năng tổng quát hóa kết quả trong ngành sẽ thấp, khó áp dụng các kết luận và đề xuất trong nghiên cứu này cho địa phương khác. Thứ ba, cỡ mẫu nghiên cứu ban đầu là 330 quan sát, tuy nhiên chỉ tổng kết 299 quan sát hợp lệ, tuy đủ điều kiện đưa vào nghiên cứu nhưng tính đại diện cho tổng thể chưa tốt. Thứ tư, nghiên cứu chỉ làm rõ 03 yếu tố thúc đẩy và 03 yếu tố kìm hãm mặc dù trên thực tế vẫn còn nhiều yếu tố. Cuối cùng, nghiên cứu dừng lại ở phân tích hồi quy bội để xem xét mối quan hệ một chiều của yếu tố thúc đẩy và kìm hãm ý định mua thực phẩm hữu cơ, vì vậy độ tin cậy không cao bẳng phương pháp phân tích hiện đại như cấu trúc tuyến tính SEM.

\section{4 Định hướng nghiên cứu tiếp theo}

Thứ nhất, nên lựa chọn phương pháp chọn mẫu phân tầng vì tính chính xác, đại diện cao. Thứ hai, gia tăng kích thước mẫu và phạm vi nghiên cứu để thu hồi kết quả mang tính đại diện mẫu, độ chính xác cao và có thể đề xuất hàm ý quản trị mang tính thực tế và ứng dụng ngay vào thực tiễn. Thứ ba, xem xét thêm yếu tố thúc đẩy khác như: chuẩn chủ quan và yếu tố kìm hãm như: rào cản truyền thống, hình ảnh cũng như kiểm tra mối tương quan giữa các yếu tố này với ý định mua thực phẩm hữu cơ. Cuối cùng, sử dụng mô hình cấu trúc SEM để ước lượng đồng thời phần tử trong tổng thể, mối quan hệ nhân quả giữa các khái niệm, đo lường mối quan hệ ổn định, không ổn định, nhân tố ảnh hưởng trực tiếp, gián tiếp.

\section{TÀI LIỆU THAM KHẢO}

Ajzen, I., (1991). The theory of planned behavior. Organizational Behaviour and Human Decision Processes, 50, 1979-211.

[1] Ajzen, I. and Fishbein, M. (1975). Belief, attitude, intention and behavior. An Introduction to theory and research. Reading, Mass: Addison-Wesley.

[2] Bagozzi, R. P. (1982). A field investigation of causal relations among cognitions, affect, intention. Journal of Marketing Research, 562-571.

[3] Basha, M. B., \& Lal, D. (2019). Indian consumers' attitudes towards purchasing organically produced foods: An empirical study. Journal of Cleaner Production, 215, 99-111.

[4] Birch, D., Memery, J., \& De Silva Kanakaratne, M. (2018). The mindful consumer: Balancing egoistic and altruistic motivations to purchase local food. Journal of Retailing and Consumer Services, 40(October 2017), 221-228.

[5] Blackwell, M. a. (2005). Price Sensitivity for Electronic Entertainment: Determinants and Consequences.

[6] Chekima, B., Chekima, K., \& Chekima, K. (2019). Understanding factors underlying actual consumption of organic food: The moderating effect of future orientation. Food Quality and Preference, 74(June), 49-58. 
[7] Ditlevsen, K., Sandøe, P., \& Lassen, J. (2019). Healthy food is nutritious, but organic food is healthy because it is pure: The negotiation of healthy food choices by Danish consumers of organic food. Food Quality and Preference, 71(May 2018), 46-53.

[8] Elbeck Matt and Tirtiroglu Ercan (2008). Qualifying Purchase Intensions Using Queceing Theory. Journal of Applied Quantitative Method, Vol. 3 No. 2, pp.

[9] Fleseriu, C., Cosma, S. A., \& Bocanet, V. (2020). Values and Planned Behaviour of the Romanian Organic Food Consumer. Sustainability, 12, 1-21.

[10] Ghali, Z., \& Hamdi, R. (2015). The Purchase and Consumption Motivations of an Organic Product by the Tunisian Consumer: an application on the Prickly Pear Seed Oil (PPS). Journal of North African Research in Business, 16, 220428.

[11] Han, H., Hsu, H., \& Lee, J. (2009). Empirical investigation of the roles of attitudes toward green behaviors, overall image, gender, and age in hotel customers' eco-friendly decision-making process. Journal of Hospitality Management, 28(4), 519-528.

[12] Hair, J. F. (2010). Multivariate data analysis. Pearson College Division.

[13] Hansen, T., Sørensen, M. I., \& Eriksen, M. L. R. (2018). How the interplay between consumer motivations and values influences organic food identity and behavior. Food Policy, 74(October 2017), 39-52.

[14] Herzberg, F., Mausner, G., \& Snyderman, B. B. (1996). Work and the nature of management. The World Publishing Company.

[15] Howard, J. A. and Sheth, J. N. (1967). A Theory of Buyer Behavior, in Moyer, R. (ed.) "Changing Marketing System", Proceedings of the 1967 Winter Conference of the American Marketing Association AMA, 253-262.

[16] Huang, Y., Yang, M. and Wang, Y., 2014. Effects of green brand on green purchase intention. Marketing Intelligence \& Planning, 32(3), pp.250-268.

[17] Kareklas, I., Carlson, J. R., \& Muehling, D. D. (2014). "I eat organic for my benefit and yours": Egoistic and altruistic considerations for purchasing organic food and their implications for advertising strategists. Journal of Advertising, 43(1), 18-32.

[18] Kushwah, S., Dhir, A., Sagar, M., \& Gupta, B. (2019). Determinants of organic food consumption. A systematic literature review on motives and barriers. Appetite, 143(October 2018), 104402.

[19] Laukkanen, T. (2016). Consumer adoption versus rejection decisions in seemingly similar service innovations: The case of the Internet and mobile banking. Journal of Business Research, 69(7), 2432-2439.

[20] Lee, H.-J., \& Yun, Z.-S. (2015). Consumers perceptions of organic food attributes and cognitive and affective attitudes as determinants of their purchase intentions toward organic food. Food Quality and Preference, 39, 259-267.

[21] Long-Yi Lin, C.-Y. L. (2010). Marketing, and trust on purchase intention: the moderating effects of word-ofmouth. Chicago: Emerald Group Publishing Limited.

[22] Molinillo, S., Vidal-Branco, M., \& Japutra, A. (2020). Understanding the drivers of organic foods purchasing of millennials: Evidence from Brazil and Spain. Journal of Retailing and Consumer Services, 52, 101926.

[23] Mullett, G. M. and Karson, M. J. (1985). Analysis of Purchase Intent Scales Weighted by Probability of Actual Purchase. Journal of Marketing Research, 93-96.

[24] Nguyen, H. V., Nguyen, N., Nguyen, B. K., Lobo, A., \& Vu, P. A. (2019). Organic food purchases in an emerging market: The influence of consumers' personal factors and green marketing practices of food stores. International Journal of Environmental Research and Public Health, 16(6).

[25] Nuttavuthisit, K., \& Thøgersen, J. (2017). The Importance of Consumer Trust for the Emergence of a Market for Green Products: The Case of Organic Food. Journal of Business Ethics, 140(2), 323-337.

[26] Pham, T. H., Nguyen, T. N., Phan, T. T. H., \& Nguyen, N. T. (2019). Evaluating the purchase behaviour of organic food by young consumers in an emerging market economy. Journal of Strategic Marketing, 27(6), $540-556$. 
[27] Ram, S., \& Sheth, J. N. (1989a). Consumer Resistance to Innovations: The Marketing Problem and its solutions. Journal of Consumer Marketing, 6(2), 5-14.

[28] Ramayah, T., Lee, J., \& Mohamad, O. (2010). Green product purchase intention: Some insights from a developing country 54(12), 1419-1427.

[29] Rey-Moreno, M., \& Medina-Molina, C. (2020). Dual models and technological platforms for efficient management of water consumption. Technological Forecasting \& Social Change, 150, 119761.

[30] Rizzo, G., Borrello, M., Guccione, G. D., Schifani, G., \& Cembalo, L. (2020). Organic food consumption: The relevance of the health attribute. Sustainability (Switzerland), 12(2).

[31] Schrank, Z., \& Running, K. (2018). Individualist and collectivist consumer motivations in local organic food markets. Journal of Consumer Culture, 18(1), 184-201.

[32] Shamsi, H. R., Najafabadi, M. O., \& Hosseini, S. J. F. (2020). Designing a three-phase pattern of organic product consumption behaviour. Food Quality and Preference, 79(November 2018), 103743.

[33] Sondhi, N. (2014). Assessing the organic potential of urban indian consumers. British Food Journal,116(12), 1864-1878.

[34] Sultan, P., Tarafder, T., Pearson, D., \& Henryks, J. (2020). Intention-behaviour gap and perceived behavioural control-behaviour gap in theory of planned behaviour: moderating roles of communication, satisfaction and trust in organic food consumption. Food Quality and Preference, 81, 103838.

[35] Tandon, A., Dhir, A., Kaur, P., Kushwah, S. \& Salo, J. (2020a). Behavioral reasoning perspectives on organic food purchase, Appetite, 104786 In Press.

[36] Teng, C. C., \& Lu, C. H. (2016). Organic food consumption in Taiwan: Motives, involvement, and purchase intention under the moderating role of uncertainty. Appetite, 105, 95-105.

[37] Van Doorn, J., \& Verhoef, P. C. (2015). Drivers of and Barriers to Organic Purchase Behavior. Journal of Retailing, 91(3), 436-450.

[38] Willer, H., Schlatter, B., Trávníček, J., Kemper, L., \& Lernoud, J. (2020). The World of Organic Agriculture. In W. Helga, S. Bernhard, J. Trávníček, L. Kemper, \& J. Lernoud (Eds.), The World of Organic Agriculture. Research Institute of Organic Agriculture (FiBL) and IFOAM - Organics International.

Ngày nhận bài: 29/04/2021

Ngày chấp nhận đăng: 08/07/2021 